\title{
АНАЛИЗ ОБРАБАТЫВАЮЩИХ ПРОИЗВОДСТВ В РЕИНДУСТРИАЛИЗАЦИОННОМ АСПЕКТЕ *
}

\author{
(C) 2018 Данилов Иван Петрович \\ доктор экономических наук, профессор \\ Чувашский государственный университет имени И.Н. Ульянова \\ 428015, г. Чебоксары, Московский пр-т, д. 15 \\ (c) 2018 Морозова Наталия Витальевна \\ кандидат экономических наук
}

Зав. кафедрой государственного и муниципального управления и региональной экономики

Чувашский государственный университет имени И.Н. Ульянова

428015, г. Чебоксары, Московский пр-т, д. 15

( 2018 Ладыкова Татьяна Ивановна

кандидат экономических наук, доцент

Чувашский государственный университет имени И.Н. Ульянова

428015, г. Чебоксары, Московский пр-т, д. 15

(c) 2018 Краснов Андрей Георгиевич

кандидат экономических наук

старший научный сотрудник Проблемной научно-исследовательской лаборатории

«Моделирование и прогнозирование социально-экономических процессов и систем»

Чувашский государственный университет имени И.Н. Ульянова

428015, г. Чебоксары, Московский пр-т, д. 15

\section{(c) 2018 Васильева Инесса Анатольевна}

старший преподаватель

Чувашский государственный университет имени И.Н. Ульянова

428015, г. Чебоксары, Московский пр-т, д. 15

E-mail:inka107@mail.ru

В статье приведены основные результаты анализа потенциала реиндустриализации Российской Федерации на основе 11 показателей, характеризующих состояние обрабатывающих производств за период 2005-2016 гг. в федеральных округах. Настоящая работа является продолжением исследования теории и практики реиндустриализации, направленного на обеспечение повышение эффективности функционирования и конкурентоспособности российской экономики. В разрезе федеральных округов проведенный анализ позволяет сделать вывод о том, что отмечается качественное ухудшение как фактического состояния, так и прогнозируемых перспектив развития обрабатывающих производств. Вследствие этого отмечается наличие негативного процесса снижения технологического потенциала реиндустриализации в экономике Российской Федерации. Предложенная методика может использоваться при оценке потенциала реиндустриализации как по отдельным регионам, так и в целом по Российской Федерации.

Ключевые слова: реиндустриализация, обрабатывающие производства, матрица обрабатывающих производств, инвестиции, федеральные округа, Приволжский ФО.

Реиндустриализация российской экономики является, по нашему мнению, концепцией, синтезирующей разные направления и пути развития российской промышленности с целью достижения ее соответствия требованиям современного и последующего технологического укладов, что будет способствовать удовлетворению национальных потребностей, обладать высокой международной конкурентоспособностью, позволяющее экспортировать значительные объемы продукции, производящихся обрабатывающими производствами [1, С.144].

* Статья подготовлена при финансовой поддержке РФФИ в рамках научного проекта № 17-02-00401-ОГН. 
Понятие «реиндустриализация» означает реорганизацию отраслей промышленности с тем, чтобы повысить их конкурентоспособность в сравнении с иностранными товарами как внутри страны, так и на международных рынках [2, С.11]. Кроме того, под реиндустриализацией понимают это комплекс мероприятий стратегического характера, применяемых государством в отношении повышения конкурентоспособности национальной промышленности. Чаще всего эти мероприятия носят институциональный характер [3, С.59]. При этом реиндустриализация должна базироваться на высокотехнологичном машиностроительном комплексе [4, С.58].

Применительно к реиндустриализации экономики РФ выделяются 3 основных направления ее реализации: во-первых, в существенной степени совпадающее с индустриализацией, реализованной в СССР, во-вторых, осуществляемое в соответствии с потребностями в определенной продукции в условиях действия экономических санкций, в-третьих, связанное с созданием новых корпораций [5, С.77-78].

Институционализация реиндустриализации применительно к современной российской экономике, на наш взгляд, включает формирование экономических отношений и институтов, направленных на ускорение подключения России к четвертой промышленной революции через усиление интеграции производства с наукой и образованием, изменение отраслевой структуры промышленного производства в пользу увеличения доли передовых технологий (цифровое проектирование и моделирование, включая суперкомпьютерный инжиниринг, новые материалы, в первую очередь, композиционные материалы, метаматериалы, металлопорошки, аддитивные и гибридные технологии, гибкие производственные ячейки, робототехнические комплексы, датчики, промышленный интернет, большие данные, технологии виртуальной и дополненной реальности, экспертные системы и искусственный интеллект). Реинституционализация в промышленности целеориентирована на создание промышленной высокотехнологичной культуры, формирующей спрос на инновации (и в т.ч., на высокоинтеллектуальные трудовые ресурсы) со стороны производственных предприятий, и стимулирование инвестиции в инновационный сектор [6, С.78].

Развитая обрабатывающая промышленность выступает важным фактором, способствующим росту экономической, научно-технологической и военной безопасности страны, устойчивости финансовой системы, здравоохранения, совершенствованию компьютерных и цифровых технологий, средств связи, создания основ новых технологических укладов. Кроме того, от уровня качественной развитости обрабатывающей промышленности зависит как обороно-промышленный потенциал России, так и ее совокупный производственный потенциал [7, С.54].

О важности развития обрабатывающей промышленности свидетельствует и то обстоятельство, что министерство промышленной политики Индии опубликовало в ноябре 2011 г. «Политику развития национальной обрабатывающей промышленности», которая предусматривает увеличение доли последней в ВНП страны с 16 до 25\% к 2022 г. Главной задачей данной политики является создание национальных зон обрабатывающей промышленности и инвестиций, которые будут освобождены от налогов, получат финансовые льготы и станут развиваться как автономные самоуправляемые области в партнерстве с частным сектором. Индия также ставит цель в течение десяти лет увеличить свою долю в глобальных прямых иностранных инвестициях с 1,3 до 5\% [8].

Применительно к США утверждается, что главным звеном на пути обеспечения стремлений Америки достичь высоких и устойчивых темпов экономического роста, может быть только обрабатывающая промышленность [9]. Реиндустриализация важна не только сама по себе, она должна рассматриваться как главное средство повышения эффективности производства, увеличения темпов роста производительности труда, роста реальной заработной платы и объема производства, т.е. как средство достижения важнейших целей экономической политики.

Для анализа потенциала реиндустриализации в федеральных округах Российской Федерации предлагается использовать официальные статистические данные Госкомстата РФ. При этом необходимо учитывать, что публикуемые абсолютные и относительные статистические показатели не позволяют объективно оценить качественный уровень потенциала реиндустриализации, особенно при проведении межрегиональных сравнений. Поэтому ранее было предложено использовать для этих целей методику оценки потенциала реиндустриализации в регионах РФ, базирующуюся на расчете его инте- 
грального индекса [10, 11].

На основе анализа имеющихся подходов к оценке потенциала реиндустриализации федеральных округов Российской Федерации нами предлагаются к использованию следующие укрупненные блоки показателей, характеризующие его основные составляющие: основные фонды и инвестиции, обрабатывающие производства, социальный блок, компьютерные технологии, наука и инновации.

В блок «обрабатывающие производства», на наш взгляд, следует включить следующие показатели (на основе которых необходимо рассчитывать 11 индексов): удельный вес обрабатывающих производств в отраслевой структуре валовой добавленной стоимости (П1); удельный вес обрабатывающих производств в структуре основных фондов (П2); удельный вес обрабатывающих производств в структуре ввода в действие основных фондов (\%) (П3); степень износа основных фондов в обрабатывающих производствах (\%) (П4); удельный вес полностью изношенных основных фондов в обрабатывающих производствах (\%) (П5); индексы производства по виду экономической деятельности «обрабатывающие производства» (в \% к предыдущему году) (П6); металлургическое производство и производство готовых металлических изделий, производство машин, транспортных средств и оборудования, производство электрооборудования, электронного и оптического оборудования в структуре отгруженной продукции обрабатывающих производств (\%) (П7); удельный вес убыточных организаций обрабатывающих производств (\%) (П8); фондовооруженность в обрабатывающих производствах (млн.руб. / занятого) (П9); фондоотдача в обрабатывающих производствах (руб. на 1 руб. основных фондов) (П10); коэффициент ввода основных фондов в обрабатывающих производствах (стоимость введенных основных фондов / стоимость основных фондов) (П11)*.

Далее проведем анализ динамики изменения показателей, характеризующих обрабатывающие производства в разрезе федеральных округов Российской Федерации. Удельный вес обрабатывающих производств в отраслевой структуре валовой добавленной стоимости (\%)
(П1) в 2016 г. был максимальным в Приволжском ФО (23,7\%), минимальным - в Дальневосточном ФО (5,3\%). По данному показателю отмечалась отрицательная динамика как максимального, так и минимального его значения - 27,9\% в 2005 г. в Сибирском ФО и 7,7\% в Дальневосточном ФО, соответственно.

Показатель П2 (удельный вес обрабатывающих производств в структуре основных фондов (\%)) в 2016 г. принимал наибольшее значение в Приволжском ФО (15,9\%), наименьшее - в Дальневосточном ФО (3,3\%). При этом максимальное значение возросло, а минимальное уменьшилось $-13,2 \%$ в 2005 г. в Приволжском ФО и 4,7\% в Дальневосточном ФО - соответственно. При этом данный показатель был максимальным в Приволжском ФО и минимальным в Дальневосточном ФО в течение всего анализируемого периода.

Значения показателя П3 (удельный вес обрабатывающих производств в структуре ввода в действие основных фондов (\%)) в 2016 г. были максимальными в Приволжском ФО (21,8\%) и минимальными - в Дальневосточном ФО (5,0\%). В течение анализируемого периода как максимальное, так и минимальное его значения уменьшились - 24,5\% в 2010 г. в Приволжском ФО и 6,3\% в Дальневосточном ФО - соответственно. Данный показатель принимал максимальные значения в Приволжском ФО (20102016 гг.), а в Дальневосточном ФО (2010-2016 гг.) имел самые низкие значения.

В 2016 г. величина показателя П4 (степень износа основных фондов в обрабатывающих производствах (\%)) была самой высокой в Северо-Западном ФО $(51,1 \%)$ и самой низкой - в Дальневосточном ФО (38,0\%). Вместе с этим происходил рост максимального и минимального показателя в сравнении с 2005 г. (49,5\% в Приволжском ФО и 37,1\% в Дальневосточном ФО соответственно).

По показателю П5 (удельный вес полностью изношенных основных фондов в обрабатывающих производствах (\%)) в 2016 г. максимальное значение отмечалось в Северо-Западном ФО (19,0\%), минимальное - в Северо-Кавказском ФО (9,8\%). По данному показателю отмечался рост как максимального, так и минимального

\footnotetext{
" Примечание. При расчете индекса П1 использовался прогноз на 2016 г. показателя, т.к. органами Госкомстата в 2017 г. предоставлялась актуальная информация по данному показателю в разрезе федеральных округов только за 2015 г. При расчете индексов П3, П5, П11 показатели использовались, начиная с 2010 г., вследствие того, что Госкомстат в региональном разрезе предоставляет данную информацию с 2010 г.
} 
его значения - 17,4\% в 2010 г. в Приволжском ФО и 7,4\% в Дальневосточном ФО - соответственно.

Показатель П6 (индексы производства по виду экономической деятельности «обрабатывающие производства» (в \% к предыдущему году)) в 2016 г. принимал наибольшее значение в Северо-Кавказском ФО (109,1\%), наименьшее - в Сибирском ФО (97,3\%). При этом как максимальное, так и минимальное его значения уменьшились $-120,8 \%$ в 2005 г. в Северо-Кавказском ФО и $104,2 \%$ в Сибирском ФО - соответственно.

Показатель П7 (металлургическое производство и производство готовых металлических изделий, производство машин, транспортных средств и оборудования, производство электрооборудования, электронного и оптического оборудования в структуре отгруженной продукции обрабатывающих производств (\%)) в 2016 г. принимал наибольшее значение в Уральском ФО (48,4\%), наименьшее - в Северо-Кавказском ФО (18,6\%). При этом максимальное значение уменьшилось, а минимальное возросло - 56,3\% в 2005 г. в Уральском ФО и 15,6\% в Северо-Кавказском ФО - соответственно.

Значения показателя П8 (удельный вес убыточных организаций обрабатывающих производств (\%)) в 2016 г. были максимальными в Дальневосточном ФО (36,5\%) и минимальными - в Северо-Кавказском ФО $(25,1 \%)$. В течение анализируемого периода как максимальное, так и минимальное его значения уменьшились $46,9 \%$ в 2005 г. в Дальневосточном ФО и 31,2\% в Северо-Западном ФО - соответственно.

В 2016 г. величина показателя П9 (фондовооруженность в обрабатывающих производствах (млн. руб. / 1 занятого)) была самой высокой в Уральском ФО $(2,66)$ и самой низкой - в Северо-Кавказском ФО $(0,89)$. Вместе с этим происходило уменьшение максимального и минимального показателя в сравнении с 2005 г. (6,965 в Дальневосточном ФО и 2,47 в Приволжском ФО соответственно).

По показателю П10 (фондоотдача в обрабатывающих производствах (руб. на 1 руб. основных фондов)) в 2016 г. максимальное значение было в Центральном ФО (3,03 руб. на 1 руб. основных фондов), минимальное - в Северо-Кавказском ФО (1,24 руб. на 1 руб. основных фондов). По данному показателю отмечалась положительная динамика как максимального, так и минимального его значения - 0,284 руб. на 1 руб. основных фондов в 2005 г. в Приволжском ФО и 0,059 руб. на 1 руб. основных фондов в Дальневосточном ФО - соответственно.

Показатель П11 (коэффициент ввода основных фондов в обрабатывающих производствах (стоимость введенных основных фондов / стоимость основных фондов)) в 2016 г. принимал наибольшее значение в Южном ФО $(0,171)$, наименьшее - в Приволжском ФО (0,094). При этом как максимальное, так и минимальное его значения возросли $-0,014$ в 2010 г. в Приволжском ФО и 0,004 в Дальневосточном ФО - соответственно.

Обобщенные результаты проведенного исследования можно отразить в виде матрицы, где по вертикали отражается динамика максимальных значений, а по горизонтали - минимальных (табл. 1).

Анализ состояния и процессов, протекающих

Таблица 1. Матрица обрабатывающих производств в разрезе федеральных округов Российской Федерации

\begin{tabular}{|c|c|}
\hline $\begin{array}{c}\text { Максимальное значение показателя возросло, } \\
\text { минимальное - уменьшилось }\end{array}$ & $\begin{array}{c}\text { Максимальное и минимальное значение } \\
\text { показателей возросло }\end{array}$ \\
\hline $\begin{array}{l}\text { П2 - удельный вес обрабатывающих производств в } \\
\text { структуре основных фондов }\end{array}$ & $\begin{array}{l}\text { П4- степень износа основных фондов в обрабатыва- } \\
\text { ющих производствах } \\
\text { П5 - удельный вес полностью изношенных основных } \\
\text { фондов } \\
\text { П10- фондоотдача } \\
\text { П11 - коэффициент ввода основных фондов }\end{array}$ \\
\hline $\begin{array}{l}\text { П1 - удельный вес обрабатывающих производств в } \\
\text { отраслевой структуре валовой добавленной стоимо- } \\
\text { сти } \\
\text { П3 - удельный вес обрабатывающих производств в } \\
\text { структуре ввода в действие основных фондов } \\
\text { П6 - индексы производства } \\
\text { П8 - удельный вес убыточных организаций } \\
\text { П9 - фондовооруженность }\end{array}$ & $\begin{array}{l}\text { П7 - удельный вес металлургического производ- } \\
\text { ства и производства готовых металлических изде- } \\
\text { лий, производства машин, транспортных средств и } \\
\text { оборудования, производства электрооборудования, } \\
\text { электронного и оптического оборудования в струк- } \\
\text { туре отгруженной продукции обрабатывающих } \\
\text { производств }\end{array}$ \\
\hline $\begin{array}{c}\text { Максимальное и минимальное значение } \\
\text { показателей уменьшилось }\end{array}$ & $\begin{array}{c}\text { Максимальное значение показателя } \\
\text { уменьшилось, минимальное - возросло }\end{array}$ \\
\hline
\end{tabular}


в обрабатывающих производствах федеральных округов Российской Федерации в течение 11 лет (2005-2016 гг.) позволяет сделать следующие основные выводы. В качестве положительных факторов можно выделить рост максимальных и минимальных значений фондоотдачи (П10) и коэффициента ввода основных средств, а также уменьшение максимальных и минимальных значений удельного веса убыточных организаций (П8). К условно положительным факторам можно отнести рост максимального и уменьшение минимального удельного веса обрабатывающих производств в структуре основных фондов (П2).

K факторам, отрицательно влияющих на функционирование обрабатывающих производств можно отнести снижение максимальных и минимальных значений удельного веса обрабатывающих производств в отраслевой структуре валовой добавленной стоимости (П1), удельного веса обрабатывающих производств в структуре ввода в действие основных фондов (П3), индексов производства в обрабатывающих производствах (П6), фондовооруженности (П9), а также рост максимальных и минимальных значений степени износа основных фондов (П4) и удельного веса полностью изношенных основных фондов в обрабатывающих производствах (П5). К условно отрицательным можно отнести такой фактор, как снижение максимального зна- чения и рост минимального удельного веса металлургического производства и производства готовых металлических изделий, производства машин, транспортных средств и оборудования, производства электрооборудования, электронного и оптического оборудования в структуре отгруженной продукции обрабатывающих производств (П7).

В заключение можно отметить, что проведенное исследование основных показателей, характеризующих функционирование обрабатывающих производств в Российской Федерации в разрезе федеральных округов позволяет сделать вывод о том, что отмечается качественное ухудшение как фактического состояния, так и прогнозируемых перспектив их развития. Вследствие этого можно отметить наличие негативного процесса снижения технологического потенциала реиндустриализации в экономике Российской Федерации.

В качестве направлений дальнейших исследований исследований обрабатывающих производств могут выступать индексный анализ предложенных показателей, а также рейтинговая оценка федеральных округов, а также регионов, входящих в тот или иной федеральный округ, для выявления общего и специфичного в функционировании и развитии обрабатывающих производств в региональном аспекте.

\section{Библиографический список}

1. Безлепкина Н.В., Кононова Е.Н., Курносова Е.А. Процессы индустриализации, деиндустриализации и реиндустриализации в эволюции российской экономики // Вестник СамГУ. 2015. № 9/2 (131) С. 137-149.

2. Захаров А.Н. Проблема реиндустриализации мировой экономики // Российский внешнеэкономический вестник. 2017. № 8. С. 3-14.

3. Дьячков А.С., Дьяченко О.В. Перспективы реиндустриализации металлургического комплекса УрФО // Вестник ЧелГУ.- Экономические науки. Вып. 53. 2016. № 6 (388). С. 58-67.

4. Колесник E.А. Машиностроение как основа реиндустриализации экономики России // Вестник ОмГУ. Серия: Экономика. 2015. № 4. С. 51-59.

5. Корнев А.К., Максимщова С.И., Трещина С.В. Опыт мирового индустриального развития и реиндустриализация отечественной экономики // Проблемы прогнозирования. 2015. № 5. С. 63-79.

6. Белокрылова О.С., Шитова А.С. Промышленная реинституционализация как предпосылка реиндустриализации экономики России // Государственное и муниципальное управление. Ученые записки СКАГС.2017.- С. 74-80.

7. Корнев А.К. Производственный потенциал России: повышение конкурентоспособности обрабатывающей промышленности // Проблемы прогнозирования. 2014. № 5 (146). С. 53-69.

8. Кондратьев В.Б. Свежее дыхание промышленной политики [Электронный ресурс]. Режим доступа: http://www.perspektivy.info/rus/ekob/svezheje_dyhanije_pro-myshlennoj_politiki_2014-05-22.htm

9. Ture N. Supply Side Policies for Reindustrialization // Reindustrialization: Implications for US Industrial policy / Ed. by Thornton R. et al.- Greenwich (Conn.). L., 1984.

10. Данилов И.П., Михайлова С.Ю. Методологические аспекты определения регионального потенциала реиндустриализации // Вестник Чувашского государственного университета. 2016. № 3. С. 28-31. 
11. Данилов И.П., Михайлова С.Ю, Морозова Н.В., Ладыкова Т.И. Практические аспекты оценки потенциала реиндустриализации федеральных округов РФ // Вестник экономики, права и социологии. 2016. № 4. С. 23-26.

Поступила в редакцию 31.08.2018 